\title{
The levonorgestrel intrauterine system as an alternative to hysterectomy for treatment of abnormal uterine bleeding
}

\begin{abstract}
Objective of the study: To study the role of levonorgestrel intra uterine system as an alternative to hysterectomy for the treatment of abnormal uterine bleeding.

Materials and methods: This was a prospective and observational study conducted in BLDE University's Shri B M Patil Medical College, Hospital and Research Centre over a period from November 2015 to August 2016 with one year follow up.40 women presented outpatient and inpatient with abnormal uterine bleeding having no contraindication for device, underwent LNG IUS insertion after the consent.

Results: After LNG-IUS insertion in DUB patients, $97.5 \%$ patients had significant decrease in blood loss and treatment failure rate $2.5 \%$ ( 1 out of 40 patients). $25 \%$ of women had normal periods, $50 \%$ of women had oligomenorrhea and $7.1 \%$ complained of intermenstrual bleeding and 1 patient requested for hysterectomy out of 40 post LNG-IUS insertion after follow up of 1 year. 1 women required removal of LNG-IUS as she was dissatisfied with LNG-IUS. Majority of the patients were satisfied with the treatment .No major side effect was noted.
\end{abstract}

Conclusion: LNG-IUS is an excellent treatment modality for patients of DUB, with good patient satisfaction. It is highly effective in controlling blood loss, well tolerated and better alternative for hysterectomy in all age groups.

Keywords: LNG-IUS, dysfunctional uterine bleeding, hysterectomy
Volume 10 Issue 2 - 2019

\author{
Pallavi H, Bidri SR \\ Department of Obstetrics and Gynaecology, BLDE University, \\ India
}

Correspondence: Dr. Pallavi Hosamani, Junior resident, Department of Obstetrics and Gynaecology, BLDE University, B 08 ,NRI Hostel, BLDEU Campus, Vijayapur, India, Tel 9739753527, Email nurturingnature60@gmail.com

Received: January 29, 2018 | Published: April 05, 2019
Abbreviations: DUB, dysfunctional uterine bleeding; AUB; abnormal uterine bleeding; LNG-IUS, levonorgestrel intrauterine system; MBL, menstrual blood loss

\section{Introduction}

About $80 \%$ of all hysterectomies are carried out for non oncological reasons and abnormal uterine bleeding is one of the most common indications for this surgical procedure in women of child bearing age. ${ }^{1}$ AUB is defined as state of abnormal uterine bleeding without any clinical detectable organic, systemic, and iatrogenic cause (pelvic pathology, e.g. tumor inflammation or pregnancy is excluded). The abnormal bleeding patterns can be annoying and adversely affect the woman's life since unpredictable or heavy bleeding can lead to psychological social, medical and sexual problems and thus necessitate appropriate and adequate treatment. ${ }^{2}$ Of all the alternative treatments for abnormal uterine bleeding, levonorgesterol intra uterine system is one among them. The local administration of levonorgesterol shows a major effect on the endometrium, which becomes atrophic and inactive with few glands and scarce mitotic activity. ${ }^{1}$ Efficacy in terms of menstrual bleeding reduction evaluated one year after the insertion of device has been reported in between $65 \%$ and $90 \%$ and adverse effects usually related to gestagens are less frequent and less severe. ${ }^{1}$

LNG-IUS is being shown to be cost effective than hysterectomy and other surgical techniques used in the management of menorrhagia ${ }^{1}$. This advantage is important in terms of health care expenditure as on increasing number of women with abnormal uterine bleeding seek for medical assistance leading to major cost implication. ${ }^{1}$

This study aims to evaluate the hysterectomy cancellation rates after a year of treatment with the levonorgesterol intra uterine system.

\section{Materials and methods}

\section{Method of collection of datal}

Source of data: This study will include outpatient and inpatient in BLDE University's Shri B. M. Patil Medical College, Hospital \& Research Centre who will be diagnosed with abnormal uterine bleeding. The patients will be informed in all respects and informed consent will be obtained.

Period of study: November 2015 to august 2016 with one year follow up.

Sampling: According to the study ${ }^{1}$ shows that efficacy of menstrual bleeding reduction in one year after the insertion of the device, $81 \%$ (average of $65 \%$ to $97 \%$ ) considering $95 \%$ confidence level and at $15 \%$ allowable error, the calculated sample size is 40 .

Methodology: Information will be collected through pre tested and structured proforma for each patient. Qualified patient will be undergoing detailed history, clinical examination and routine investigation. 
Inclusion criteria: All patients who are diagnosed as abnormal uterine bleeding will be explained about the procedure in their language and who agree to give consent will be included in the study.

\section{Exclusion criteria}

a. Pelvic infections

b. Malignant and premalignant conditions

c. Cases with pregnancy complications

d. Acute liver disease or liver tumors

e. Hypersensitivity to levonorgesterol

f. Uterine fibroids

g. Thyroid complications

h. Post menopausal bleeding

i. Bleeding diathesis

\section{Results and observation}

Patients with different obstetric history does not differ significantly, comparatively multi gravida percentage is more than nulligravida. Here P3L3 with 52.5\% and nulligravida with 2.5. 10 patients out of 40 had normal periods, 20 patients had oligomemorrhea at 1 year follow up. None of the patients followed up till 1 year, had persistent menorrhagia or polymenorrhea (Table 1) (Table 2).

Only one patient had persistent menorrhagia that underwent premature removal. The patient who had premature removal excluded from further follow up, after removal as they underwent hysterectomy. In present study, out of 40 patients, one patient underwent hysterectomy (Table 3) (Figure 1). It comes with success rate of $97.5 \%$, after one year of follow up.

Table I Percent distribution of obstetric score with no of patients

\begin{tabular}{lll}
\hline Obstetric history & No. of patients & Percentage \\
\hline Nulligravida & $\mathrm{I}$ & 2.5 \\
PILI & $\mathrm{I}$ & 2.5 \\
P2LIDI & $\mathrm{I}$ & 2.5 \\
P2L2 & 9 & 22.5 \\
P3L2DI & $\mathrm{I}$ & 2.5 \\
P3L3 & 21 & 52.5 \\
P4L4 & 5 & 12.5 \\
P5L5 & 1 & 2.5 \\
Total & 40 & 100
\end{tabular}

One patient with persistent menorrhagia, lead to premature removal and underwent hysterectomy. It comes with $2.5 \%$ of failure rate.

Comment: LNG-IUS has better results and significant reduction in bleeding over a period of one year (Figure 2) (Table 4).

The most common endometrial histopathological pattern was proliferative phase. Other patients mainly had simple endometrial hyperplasia, and secretory endometrium, and none of the patients had complex hyperplasia.
Comment: This rules out the cases of malignancies and gynecological disorders associated with the case (Figure 3).

Table 2 Menstrual patterns at baseline and at I year follow up

\begin{tabular}{|c|c|c|}
\hline Menstrual history & $\begin{array}{l}\text { No. of } \\
\text { patients }\end{array}$ & $\begin{array}{l}\text { After follow up } \\
\text { of I year }\end{array}$ \\
\hline Normal period & 0 & 25 \\
\hline 50 & & \\
\hline Intermenstrual spotting & 0 & 7.1 \\
\hline Amenorrhoea & 0 & 22.5 \\
\hline Persistent menorrhagia & 100 & 0 \\
\hline Dysmenorrhea & 0 & 10.7 \\
\hline Polymenorrhea & 0 & 0 \\
\hline Total & 40 & \\
\hline
\end{tabular}

Table 3 Percentage distribution of patients underwent hysterectomy

\begin{tabular}{lll}
\hline No. of patients & Hysterectomy & Percentage \\
\hline 39 & No & 97.5 \\
I & Yes & 2.5 \\
40 & Total & 100 \\
\hline
\end{tabular}

Table 4 Percentage distribution of patients with endometrium sampling

\begin{tabular}{lll}
\hline Endometrium sampling & $\begin{array}{l}\text { No. of } \\
\text { patients }\end{array}$ & Percentage \\
\hline Asynchronus Endometrium & $\mathrm{I}$ & 2.5 \\
Disordered Proliferative Endometrium & 3 & 7.5 \\
No Opinion Possible & $\mathrm{I}$ & 2.5 \\
Normal & $\mathrm{I}$ & 2.5 \\
Proliferative phase & 27 & 67.5 \\
Secretory Endometrium & 2 & 5 \\
Simple endometrial hyperplasia with meta & $\mathrm{I}$ & 2.5 \\
Simple endometrial hyperplasia without A & 4 & 10 \\
Total & 40 & 100 \\
\hline
\end{tabular}

Table 5 Comparison of adverse effects

\begin{tabular}{llll}
\hline Study/sample size & $\begin{array}{l}\text { Our study } \\
(\mathbf{4 0 )}\end{array}$ & $\begin{array}{l}\text { Kriplani et } \\
\text { al.(63) }\end{array}$ & $\begin{array}{l}\text { Chattopdhya } \\
\text { et al.(42) }\end{array}$ \\
\hline $\begin{array}{l}\text { Irregular bleeding } \\
\text { Perfortion }\end{array}$ & $-10 \%$ & $71 \%$ & $28.50 \%$ \\
Expulsion & $2.50 \%$ & & \\
Weight gain & - & $30.50 \%$ & $2.38 \%$ \\
Pain & - & $38 \%$ & $4.76 \%$ \\
Headache & - & $13.30 \%$ & \\
Vaginitis & $5.10 \%$ & $33.30 \%$ & \\
\end{tabular}




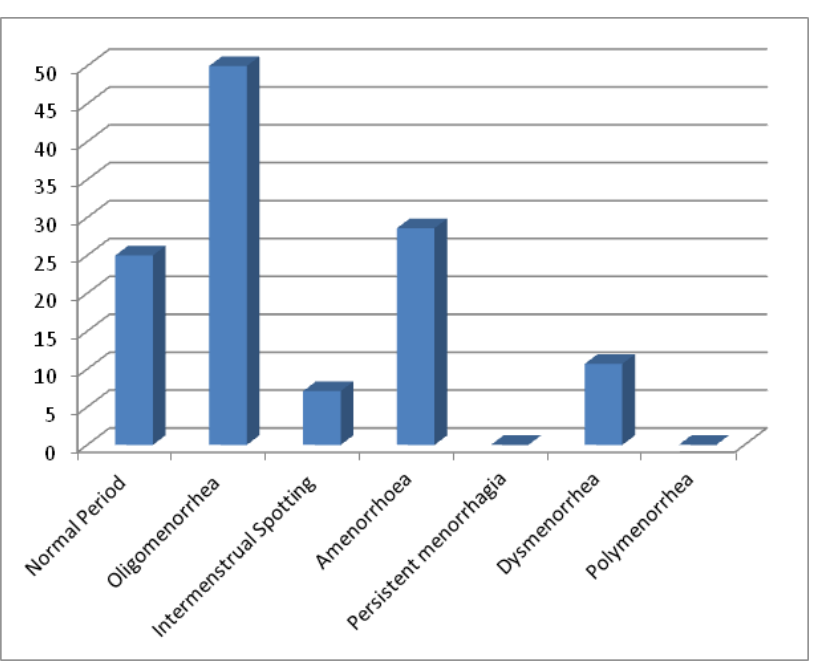

Figure I Percentage distribution of follow up of patients with abnormal uterine bleeding.

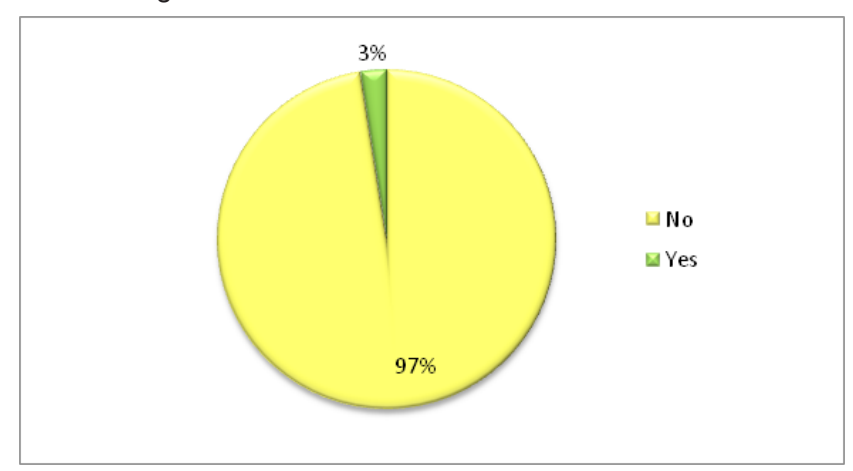

Figure 2 Number of patients undergone Hysterectomy.

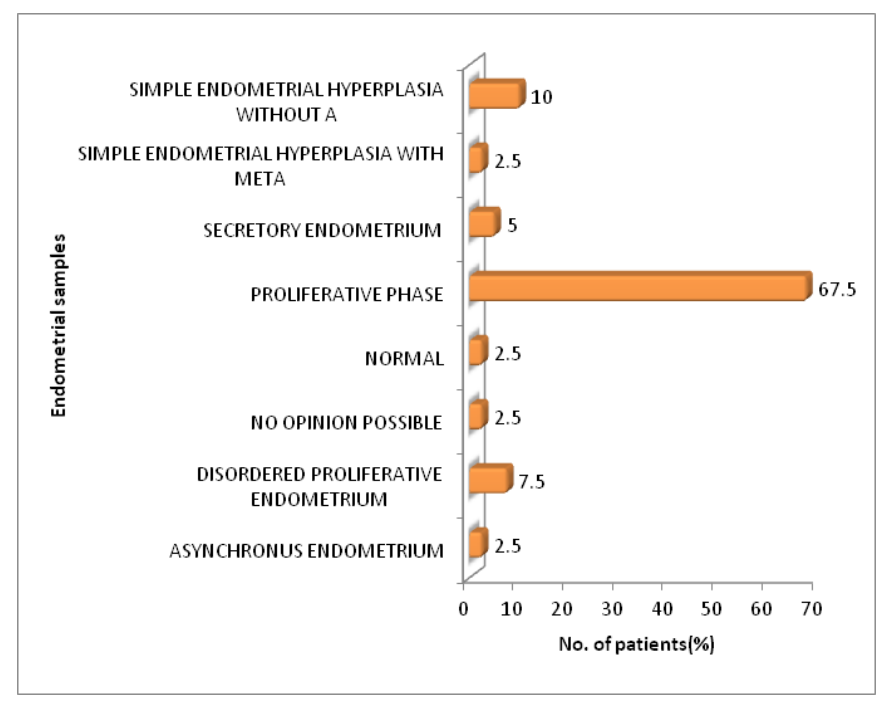

Figure 3 Endometrial samples.

\section{Discussion}

This is a prospective and observational study about the role of levonorgestrel intra uterine system as an alternative to hysterectomy for the treatment of abnormal uterine bleeding. 40 patients with dysfunctional uterine bleeding were taken for the study. It provides a non surgical alternative continuation rate of $97.5 \%$ after one year shows high acceptance.

In abnormal uterine bleeding, their in significant reduction in menstrual blood loss with the use of LNG. This effect is based on the marked local action of intrauterine release of LNG on the endometrium.

A study by Taru G et al. ${ }^{3}$ in 2013 conducted a study on the acceptability, efficacy, adverse effect and user satisfaction of levonorgestrel intrauterine system concluded that LNG IUS is a less invasive, effective treatment modality for menorrhagia.

This is an observational descriptive study where menstrual pattern, pictoral blood loss assessment, chart score, adverse effects and rate of acceptability and satisfaction were recorded over a period of one year after procedure, with the mean age of sample size 39.92years. After follow up of one year $33.87 \%$ were amenorrhic and $51.61 \%$ have regular period while $3.07 \%$ patients had irregular periods (Table 5).

A study conducted by Gupta. $\mathrm{R}$ et al. Reported good results with failure rate of only $3.4 \%$ i.e 1 out of 29 patients in DUB patients, comparatively higher in fibroid patients with $23.3 \%$ i.e 7 out of 30 .

Hemoglobin and serum ferritin levels were significantly increases in both the groups with no major side effects. LNG-IUS is an excellent treatment moality for patients of dub, with good patient satisfaction. It is also a useful treatment option in sub mucosal fibroids for symptoms of menorrhagia.

Present study has a failure rate of $2.5 \%$ i.e 1 lout of 40 .fibroid uterus were under the exclusion criteria. Singh K et al. ${ }^{4}$ found LNG IUS is highly effective in controlling bleeding and better alternative for hysterectomy with higher satisfaction in all age group of women.

Initially $37.5 \%$ of patients complained of irregular bleeding which was reduced after a year of follow up and $2^{\text {nd }}$ most complaint was irregular spotting for $32.5 \%$ people which persisted in $7.4 \%$ patients at 1 year follow up. Preliminary endometrial biopsy was done to rule out malignancy.

In our study $7.1 \%$ patients had irregular spotting after follow up of one year, histopathological report was considered.

Goni AZ et al. ${ }^{1}$ conducted a prospective observational study where 82 were enrolled with mean age of 44.3., after 1 year follow up, progressive reduction in bleeding and no of sanitary measures was observed. Significant improvement in overall health related quality of life was achieved and contributed to decrease in the large number of hysterectomies.

In our study, $97.5 \%$ were reported with patient satisfaction with LNG-IUS hysterectomies were reduced. No serious adverse effects were encountered.

A prospective observational study conducted by Lete et al. ${ }^{5}$ with 225 women with one year follow up found significant reduction of bleeding, an improved quality of life with $98 \%$ satisfication. Here mainly QoL of women treated with the ING-IUS is markedly improved, causing high levels of patient satisfaction. They regarded IUS as first choice therapy in idiopathic menorrhagia. This study had certain limitations; there was no control group for this study. Second limitation is that patient was followed up during only one year and further Analysis are required. ${ }^{6-10}$ 
Roy $\mathrm{k}^{10}$ conducted a prospective interventional comparative study conducted on women with abnormal uterine bleeding, found statistical improvement in the Hblevel after insertion of LNG-IUS. ${ }^{11-14}$

A observational study conducted by Tariq $\mathrm{N}$ to find out clinical response, side effects, and patients acceptability of levonorgestrel -releasing intrauterine system (LNG-IUS). ${ }^{15,16}$ Adult women were enrolled, where two groups were enrolled where 57 women with abnormal uterine bleeding and 16 married woman for contraception.

In group $\mathrm{A}$, at the end of one year $50.9 \%$ experienced normal cycle, $8.8 \%$ were oligomenorrhic $12.3 \%$ were amenorrhic. In group $\mathrm{B}$ menstrual pattern at the end of one year showed normal cycles in $52 \%$, oligomenorrhea in $19 \%$ and amenorrhea in $10 \%$ women. Vaginal spotting was the main complaint in $10 \%$ at the end of a year. ${ }^{17-20}$

Concluded with LNG-IUS is an effective and acceptable treatment for abnormal uterine bleeding as well as contraception .Vaginal spotting was most frequent side effect experienced by both groups. Present study comes up with minimal side effects and $97.5 \%$ success rate.

\section{Conclusion}

LNG IUS can be a good alternative to the surgical treatment for abnormal uterine Bleeding with high acceptability rate and good efficacy. Present study, shows that LNG IUS is easy to insert has a sustained effect, cost effective, and well tolerated.

Present study brought out that LNG IUS appears equally effective as hysterectomy in improving quality of life in patients of DUB. It can serve to bring down the incidence of hysterectomies.

According to our study, LNG IUS meets the effectiveness and tolerability criteria for being considered as a first choice treatment option for women with abnormal uterine bleeding. LNG IUS can help to save uterus.

\section{Acknowledgments}

None.

\section{Conflicts of interest}

The authors declare no conflicts of interest.

\section{References}

1. Goni AZ, Lacruz RL, Parico JJP, et al. The levonorgestrel intrauterine system as an alternative to hysterectomy for the treatment of idiopathic menorrhagia. Gynecol Endocrinol. 2009;25(9):581-586.

2. Shawki O, Wahba A, Magon N. Abnormal uterine bleeding in midlife: the role of levonorgestrel intrauterine system. J Midlife Health. 2013:4(1):3639.

3. Taru G, Nupur G, Sangeeta G, et al. Levornorgestrel intrauterine System (LNG IUS) in menorrahgia ; a follow -up study. Open Journal of Obstetrics and Gynecology. 2014;4(4):190-196.

4. Singh K, Bharati G, Prasad D, et al. Role of Levonorgestrel releasing intrauterine device in management of heavy menstrual bleeding:a conservative approach. Int J Reprod Contracept Obstet Gynecol. 2017;6(2):631-635.
5. Lete I, Obispo C, Izaguirre F, et al. The levonorgestrel intrauterine system(mirena) for treatment of idiopathic menorrhagia; Assessment of quality of life and satisfaction. Eur J Contracept Reprod Health Care. 2008;13(3):231-237.

6. Stewart A, Cummins C, Gold L, et al. The effectiveness of the levenorgestrol releasing intrauterine system in menorrhagia: a systematic review. BJOG. 2001;108(1):74-86.

7. Hurskainen R, Teperi J, Rissanen P, et al. Clinical outcomes and costs with the levonorgestrel - releasing intrauterine system or hysterectomy for treatment of menorrhagia: randomized trial 5-year follow-up. JAMA. 2004;291(12):1456-1463.

8. Marulies L. History of intrauterine devices. Bull NY Acid Med. 1975;51(5):662-667.

9. Seeru G, Anita SA. Non surgical lifeline for abnormal uterine bleeding(AUB)-the LNG IUS. Indian journal of Obstetrics and Gynecology Research. 2016;3(1):23-27.

10. Roy K, Kumar A. Levonorgestrel -releasing intrauterine system as an alternative therapy in abnormal uterine bleeding. $J$ Evid Based Med Healthc. 2017;42(4):2564-2568.

11. Eralil GJ. The effectiveness of Levonorgestrel Releasing intrauterine system in the treatment of heavy menstrual bleeding. J Obstet Gynaecol India. 2016;66(Suppl 1):505-512.

12. Kai J, Middleton L, Daniels J, et al. Usual Medical treatments or Levonorgestrel -IUS for women with heavy menstrual bleeding: longterm randomised pragmatic trial in primary care. $\mathrm{Br} J$ Gen Pract. 2016;66(653):e861-e870.

13. Utman N, Faheen F. Levonorgestrel Intrauterine system (LNG IUS) in menorrhagia: A three follow up study. JPMI. 2012;26(1):79-83.

14. Theodoros TD, Zepiridis L, Zafrakas M, et al. Levonorgestrel -releasing intrauterine system vs. endometrial thermal ablation for menorrhagia. Hormones (Athens). 2009;8(1):60-64.

15. Adiguzel C, Seyfettinoglu S, Aka Satar D, et al. Evaluation of quality of life and cost -effectiveness of definitive surgery and the levonorgestrel intrauterine system as treatment options for heavy menstrual bleeding. Turk J Med Sci. 2017;47(3):789-794.

16. Vilos GA, Tureanu V, Garcia M, et al. The Levonorgestrel Intrauterine System is an effective treatment in women with Abnormal Uterine bleeding and Anticoagulant thearapy. J Minim Invasive Gynecol. 2009; 16(4):480-484.

17. Oliveira N, Rosado V, Correia L, et al. Levonorgestrel intrauterine device effectiveness in heavy menstrual bleeding treatment in obese women. Acta Obstet Ginecol Port. 2014:8(4):347-353.

18. Begum R, Khanam M. Levonorgestrel releasing intrauterine system in the treatment of dysfunctional uterine bleeding. Medicine today. 2013;25(2).

19. Baxi A, Kaushal M, Ghosh A. The Levonorgestrel Intrauterine Device: an effective and acceptable alternative for the management of menorrhagia. Turkish-German Gynecol Assoc. 2008;9(4):202-205.

20. Gupta R, Dewan R, Mittal P, et al. Role of levonorgestrel releasing intrauterine system in the treatment of menorrhagia due to dysfunctional uterine bleeding and fibroid uterus. International Journal of Reproduction, Contraception, Obstetrics and Gynecology. 2014;3(3):671-677. 